\title{
Memory Support in Ambient Assisted Living
}

\author{
Ricardo Costa ${ }^{1}$, Paulo Novais ${ }^{2}$, Ângelo Costa ${ }^{2}$, and José Neves ${ }^{2}$ \\ ${ }^{1}$ CIICESI, College of Management and Technology, Polytechnic of Porto, \\ Felgueiras, Portugal \\ rcostalestgf.ipp.pt \\ ${ }^{2}$ CCTC, Departamento de Informática, Universidade do Minho, Braga, Portugal \\ \{pjon, jneves\}@di.uminho.pt, angelogoncalocostalgmail.com
}

\begin{abstract}
Human collective set of experiences makes us who we are and help us delineate a path for our ongoing life. Ageing, however, progressively limits our ability to save, in our internal memory, these same experiences, or, at least, limits our capability to remember them. The capability to remember, intrinsic to our memory, is a very important one to us, as a human been, being this what deferent's us from several other species. In this paper we present a memory assistant sub module of a bigger project, the VirtualECare, which ability will be to remember us, not our past experiences, but our routine day-to-day tasks and activities, in a somehow proactive manner, thus, allowing us to have some relaxation about them, and focus the remaining of our ability in most important facts.
\end{abstract}

Keywords: e-Health, Memory Assistant, Ambient Assisted Living, Scheduling.

\section{Introduction}

The human memory, or its collective set of memories, is what makes us who we are. These memories are the combining set of experiences of our ongoing life. They provide us with the sense of self, allow us the sensation of comfort with familiar people and surroundings, connect our past with our present and provide us data to idealize our future. Memory is no more than the concept that refers to the process of remembering [1]. Aging, especially if associated with chronic diseases, affects our ability to remember, thus affects our memory. This is something intrinsic to the human being which cannot be reversed but, with the use of the commonly named new technologies, can be minimized.

\subsection{Population Ageing Phenomena}

According to the United Nations [2], population ageing is unprecedented, without parallel in human history, and it will keep growing thru the twenty-first century, rapidly than it did in the century just past. We will not return to the young populations that our ancestors knew.

This population ageing phenomena has profound implications in many facets of the human life. One of these facets is that with ageing, memory loss becomes more and more frequent [3]. 


\subsection{Memory Assistant Software}

With the recent advances in the, so called, Information Society, computational systems, specially embedded ones, are becoming, in a natural way, part or our day-to-day activities. This fact, associated with the decrease in size and cost of devices in general, allows the use of the already available new technologies in new areas where before where impossible. One of these areas is in the aid of our memory. Some memory assistant projects and software already exist [4-9] for several years, but the FP7 Hermes [7] and the SenseCam [8] seem to be the only ones with recent activity.

HERMES is aimed to provide cognitive care. Developed in collaboration between CURE - Center for Usability Research and Engineering, INGEMA Foundation, IBM Haifa Research Lab, University of Bradford, Athens Information Technology and TXT e-Solutions. Each of these companies is located in different countries, such as Austria, Spain, UK, Greece and Italy. The project is supported by the EU under the Framework Programme 7. It tries to provide an independent living and social participation, by boosting the self-efficacy of the user (patient). The main objective is to develop a system, software and hardware, which will reduce the negative impact of declining cognitive capabilities, particularly memory. An important feature of the this project is the implementation of a monitoring system which should be able to record every action, and associated choices, of one user in order to build a associations "map" of the different events and, based on that "map", create a pattern that emulates the human memory mechanisms. Despite its ambitious goals, HERMES is still in a very early stage of development and, as so, the idealized and developed hardware/software combinations are, yet, very simple, with low effectiveness. For instance, the speech recording has to be in certain, limited, parameters in order to be converted to text and the system still needs to be, manually, trained for each user.

SenseCam developed by Microsoft, it is a wearable camera that takes photographs, passively, without the intervention of its user (patient). The objective is to report, in images, the user's day activities and what places he has been. The hardware contains some degree of automation, e.g.: light-intensity and light-color sensors, body heat detector and motion sensors. Suited to be used on a cord around the neck, it will also be possible to clip it in pockets or belts, or attach directly in clothing. Saving the images into its internal memory, the visioning of them can be as a time lapse video of the user all-day activities. Although the Microsoft Research Center admits it is memory assistant software for elderly, in fact it has no significant, on-the-fly, abilities of remembering its users of events and/or tasks. It is merely, a so called time machine, like a video camera used to record what the user has done. However it serves the purpose of remembering the user what he has done, in a determined day. It doesn't have any kind of intelligence associated and it serves merely users with total memory loss, like Alzheimer's.

\subsection{VirtualECare}

The VirtualECare project [10] is an intelligent multi-agent system able, not only to monitor, but also to interact with its users (patients and/or relatives). It can, and should, be interconnected with other computing systems running in different health care institutions, leisure centers, training facilities and/or shops. It is composed by several components/modules, interconnected through a network (e.g., LAN, MAN, WAN), having each one a specific role (Fig. 1) [11]. 


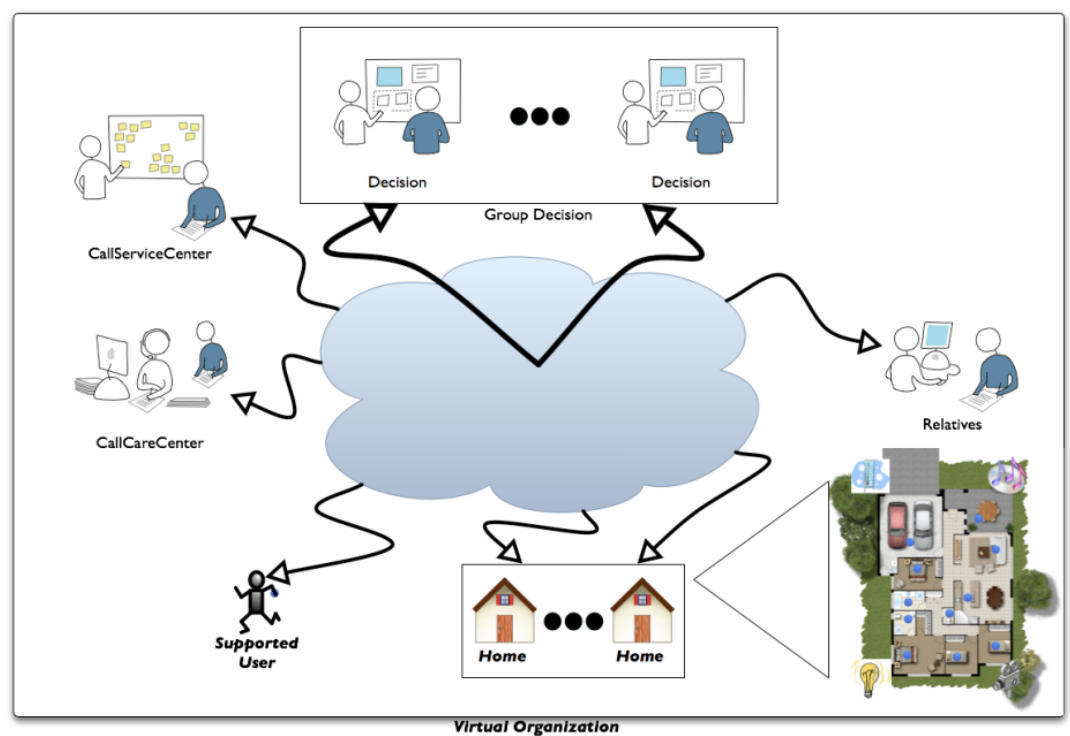

Fig. 1. VirtualECare Project

\section{2 iGenda}

The iGenda is one of the base software's in the Home and Relatives modules of the above presented project in conjunction with the monitoring one [12]. Its main objective consists in provide an intelligent organizer and/or scheduler and/or reminder to all the other modules of the VirtualECare project (e.g., GroupDecision, CallCareCenter) in order to allow them to manage the day-to-day diet, medication, activities, tasks and free time of the monitored users [12]. This way, he/she will always know, in real time even if changes are inflicted by one of the several modules, what will be the next "task" to perform.

The major goal is to create a product that will help its users to remember important information, events or tasks, or, in other words, to provide in-the-fly memory assistant. It can help, specially, people with memory loss (partial or total), by keeping his, all day, events and warn when the time to execute them as arrived, providing an increase in the quality of life and also a greater independence to the user. This module will also be able to receive information delivered by the remaining VirtualECare platform modules and organize it the most convenient way, given predefined standards. This way the user will not have to be worried about planning or scheduling events and tasks. The iGenda intends to be easy to operate by its users and will play an important role in his day-to-day life, being responsible for planning it (or week, or month). As an example, if the Group Decision module decides that the user must visit a medical center the iGenda is prepared to receive the respective information and conveniently process it, according to its level of criticism, and reorganize the user schedule in a short period of time. In order to be fully integrated in the VirtualECare architecture the iGenda archetype has to respects its standards protocols of communication [13]. Moreover, it is expected that the user is 
always in communication with the system, in order that any event of extreme importance could be, at any time, added in its agenda [14]. This system is organized in a hierarchy of states and events intended to deal with the information received (Fig. 2). To fulfill all the work mentioned, four sub-modules will be created: Agenda Manager, Free Time Manager, Conflicts Manager and Interface Manager.

\subsection{Agenda Manager}

The Agenda Manager (AM) is the bridge between the remaining VirtualECare system modules and the scheduling system, using the communication infrastructure to receive and send information. Therefore the AM is the iGenda starting point. The AM consists in a two stage sub-module application. It manages the incoming, to be scheduled, events and programs the time that triggers the Free Time Manager (FTM). It also supports the receiving of multiple events in the same message in order to increase the overall system performance. When a new task/event is received, the AM parses in order to be processed by the Conflicts Manager (CM). After being transformed, the data is delivered to the CM to be continuously assimilated and processed. The FTM is activated by the AM. The AM contains an internal clock that is configured for each user. It is defined a period of execution for the FTM, and when that period is reached the AM orders its execution. There will also be a set of rules, implemented in Prolog Language, which will be used in the CM, assuring that the new arrived events will be correctly inserted in the user agenda. When a level 1 (high priority) hierarchy conflict is detected, the system will return a message to its sender containing a high priority events overlapping warning, in order to allow the sender to reschedule it to another time. This module is also capable to communicate in with the remaining modules of VirtualECare platform, in order to report possible detected incoherence's during the processing phase of the received messages.

\subsection{Free Time Manager}

The Free Time Manager (FTM) will schedule recreational activities, according with the user health condition, in the free spaces of its calendar, in order to keep him occupied, increasing his well-being. These activities may be a very important step in order to allow an active ageing, aiming to create social and cultural dynamism, physical and educational activities, thus obtaining conviviality with others. These recreational activities are meticulously planned for each individual user based in his needs and preferences. To achieve these results, the FTM has a database which contains user's information, as, for instance, the user's favorite activities, previously approved by the Decision Group module, thus, allowing him to have, according to its eventual limitations, the best choice of physical and psychological activities at each time.

Initially we where seduced to use Scheduling Techniques (ST) to obtain the best possible arrangement of all the activities. However, we reached to the conclusion that it was not the best way of engaging the problem. We realized that implementing the user preferences system (presented above), in which the user chooses from a Decision Group module approved list, his favorites activities, it is useless to use any ST because we already have a hierarchy list and once we do not have a equal timed scheduling. We 


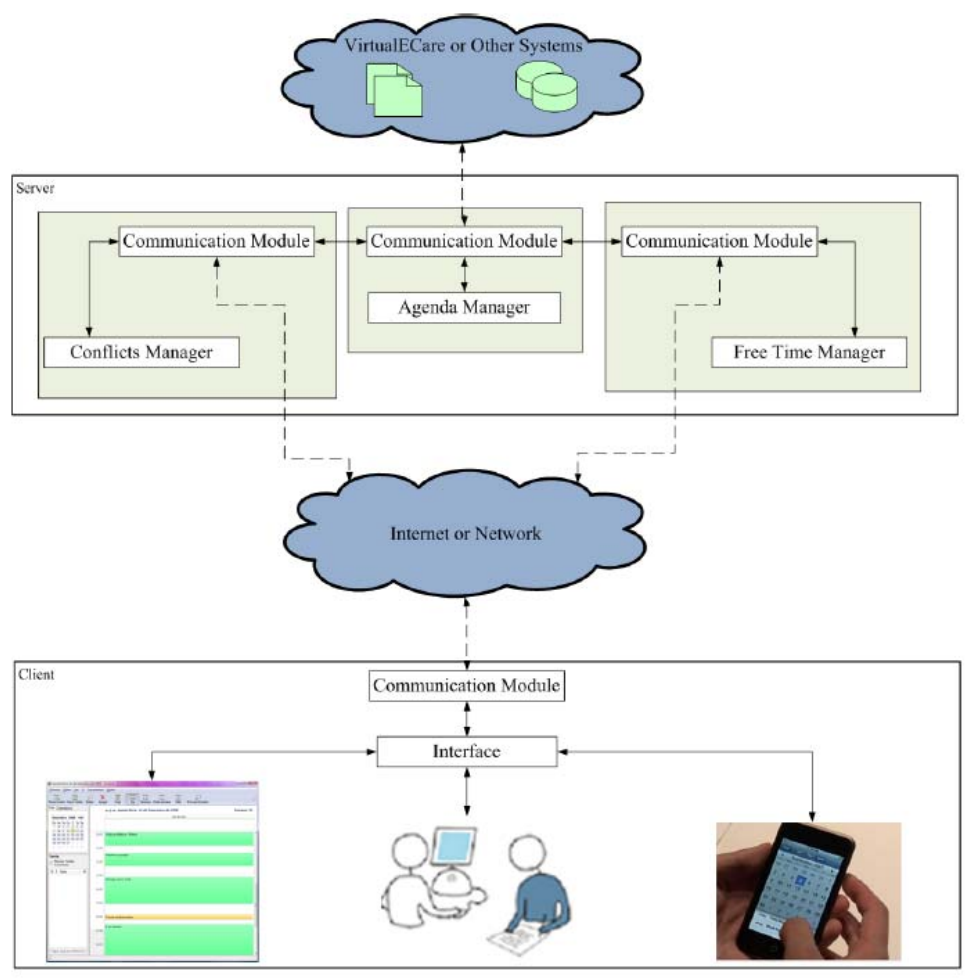

Fig. 2. iGenda Architecture

then verified that using a more simple arithmetic solution: pattern matching, was much more efficient. We simply have to match the gaps available with the time consumed by the activities from the hierarchy, pre-defined, list.

\subsection{Conflicts Manager}

The Conflicts Manager (CM) main task is to make sure that there are not any overlapping activities. This module schedules or reorganizes events that are received from the AM, always verifying they are in accordance with other, already scheduled, events. If there a collision is detected, of different hierarchic events, it can be simple decided by methods of intelligent conflicts management (the most important activities overcomes all the other ones), however, in case of overlapping events with the same priority level, the error must be reported to the GDSS (Group Decision module) in order decide how to resolve that, specific, collision.

\subsection{Interface Manager}

The IGenda sub-module interface must be, above all, intuitive and easy to use. In the implementation phase a technician should introduce the user preferences in the system, which will then be carefully analyzed by a panel of medical specialists (in the 


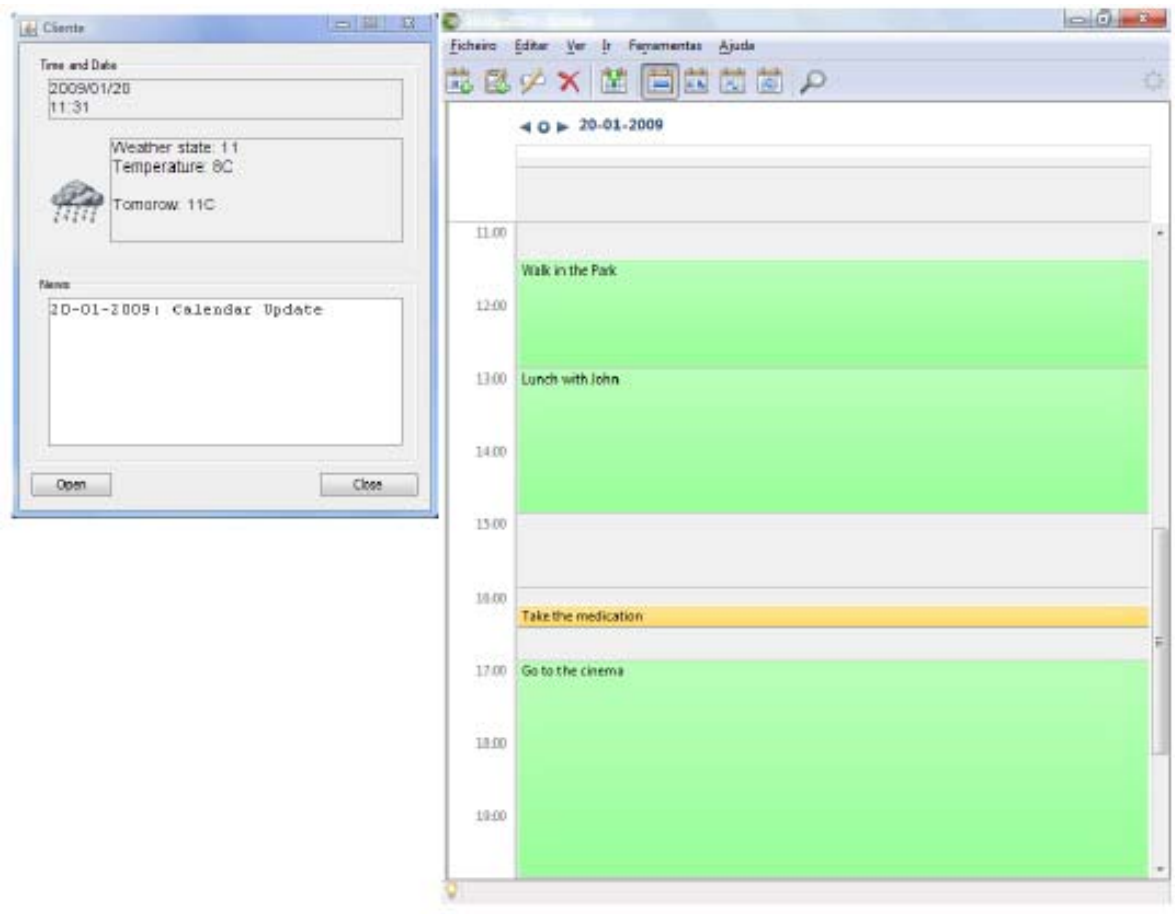

Fig. 3. Client Interface

Decision Group module) according to the user state of health (Fig. 3). The Interface consists of a main window which contains the weather and time information, and a warning notifier. This warning notifier gives the user important information about schedule updates, like new activities/events and/or important information sent directly to him (e.g., a critical warning from the GroupDecision or the CallCareCenter modules). It has also a calendar window, which is meant to be opened by the, already present in the operating system, default calendar software. The compatibility with this software is guaranteed by the using of the standard iCalendar Calendar Data (ICS) format. Is has also been developed a variable warning system responsibly to, properly, warn the user of a specific event. This warning system can be configured in two different states: always active or selective mode. In the first state, the user will always be notified in the beginning, or in the previously time it has been configured, of a specific event. Otherwise, in the selective mode this warning system has some "Intelligence" associated, been able to, through the real time analysis of the available health sensors, decide if the actual activities, not previously scheduled, is more or less important than the schedule one and act in line. For instance, if the user is actually resting, information obtained from the state of the available sensors, and the time for a activity, let say walking, is coming, the warning systems may decide that resting is more important than walking, at the present time. 


\subsection{Sample Use Scenario}

The main goal of the iGenda sub module in the VirtualECare project is to improve end user's quality of life allowing them to better enjoy the so-called active ageing.

To better understand the amplitude of the iGenda sub module, let's consider the following scenario [15]:

"John has a heart condition and wears a smart watch that takes his blood pressure three times a day. He also has a PDA, connected with his watch, which reminds him to take his medications, with the proper dosage, his several events, presents his diet, and presents his, monitored, vital signs statistics. If anything unusual arises, his PDA alerts, both, him and the Group Decision Support System (GDSS) and, at the same time, presents him with a table of possible causes and solutions for the actual condition. The GDSS has, also, access to this table so they can keep it up to date, based on his condition. Currently, John's PDA warns John is time to take 1 pill of his hearth medicament and also detects that his blood pressure is unusually high. The GDSS receives a grade $B$ alert and calls him to check what might be causing his high blood pressure (previous diagnose). At the same time John PDA presents a checklist of possible causes, and possible resolutions, to review. Meanwhile, the GDSS decides John should take 1 additional pill of his high blood pressure medicament and come to an appointment, automatically scheduled in his calendar with high priority. Additionally the GDSS decides that John diet should also be more refined and uploads the new, more refined, diet to his PDA and cancels all the physical exercises activities until the scheduled appointment."

In the above presented scenario, we realize how useful the iGenda sub module may be. It allows John to live his life without been worried if he is going to forget something important, as medication, or its proper dosage. It also allows an enormous proximity between doctor and patient, as, for instance, medicament dosage may be altered in "transit" or the taking of SOS medicaments may be ordered in line with the current condition, cancelation of activities, etc. Additionally it will allow relatives to be kept informed of his current condition.

\section{Conclusion}

In this paper we discuss the problematic associated with the ageing phenomena, the "normal" memory losses associates with it and we also present the memory assistant module of the VirtualECare project in conjunction with a position of its most recent developments. This is our first approach to human memory assist software, in order to allow a dignified active ageing of the population in general and to the elderly in particular. Our approximation to a possible resolution of this, no new, problematic is very technologically based, which may become an obstacle, especially with the elderly, but we are now starting to conducting several new developments which include the built and day-to-day test of a truly functional (with multiple devices, situations and cases) prototype in order to make the necessary adjustments introduced by real life use. We are also starting to integrate this sub module in our Simulation Environment in order, not only make high volume and adequate tests, but also to experiment odd and unexpected situations, verify the system comportment and make the necessary adjustments. 


\section{References}

1. Mohs, R.C.: HowStuffWorks "How Human Memory Works (2007), http: / / health. howstuffworks.com/human-memory.htm

2. World Population Ageing: 1950-2050. Population Division, DESA, United Nations (2001)

3. Tucker, G.: Age-Associated Memory Loss: Prevalence and Implications. Journal Watch Psychiatry (1995)

4. Lamming, M., Flynn, M.: Forget-me-not: Intimate computing in support of human memory. In: Proceedings of FRIEND21, vol. 94, pp. 2-4 (1994)

5. Rhodes, B.J.: The wearable remembrance agent: A system for augmented memory. Personal and Ubiquitous Computing 1, 218-224 (1997)

6. Kim, H.J., Burke, D.T., Dowds, M.M., George, J.: Utility of a microcomputer as an external memory aid for a memory-impaired head injury patient during in-patient rehabilitation. Brain Injury 13, 147-150 (1999)

7. Jiang, J., Geven, A., Zhang, S.: HERMES: A FP7 Funded Project towards ComputerAided Memory Management Via Intelligent Computations. In: 3rd Symposium of Ubiquitous Computing and Ambient Intelligence 2008, p. 249. Springer, Heidelberg (2008)

8. Hodges, S., Williams, L., Berry, E., Izadi, S., Srinivasan, J., Butler, A., Smyth, G., Kapur, N., Wood, K.: SenseCam: A retrospective memory aid. In: Dourish, P., Friday, A. (eds.) UbiComp 2006. LNCS, vol. 4206, pp. 177-193. Springer, Heidelberg (2006)

9. Giraldo, C., Helal, S., Mann, W.: mPCA-A mobile patient care-giving assistant for Alzheimer patients. In: Workshop Ubiquitous Computing for Cognitive Aids, UbiCog 2002 (2002)

10. Costa, R., Novais, P., Lima, L., Carneiro, D., Samico, D., Oliveira, J., Machado, J., Neves, J.: VirtualECare: Intelligent Assisted Living. In: Electronic Healthcare, vol. 1, pp. 138 144. Springer, Heidelberg (2009)

11. Costa, R., Novais, P., Machado, J., Alberto, C., Neves, J.: Inter-organization Cooperation for Care of the Elderly. In: Integration and Innovation Orient to E-Society, vol. 252, pp. 200-208. Springer, Boston (2008)

12. Carneiro, D., Costa, R., Novais, P., Neves, J., Machado, J., Neves, J.: Simulating and Monitoring Ambient Assisted Living. In: Bertelle, C., Ayesh, A. (eds.) ESM 2008, Le Havre, France, pp. 175-182 (2008)

13. Novais, P., Costa, R., Carneiro, D., Machado, J., Lima, L., Neves, J.: Group Support in Collaborative Networks Organizations for Ambient Assisted Living. Towards Sustainable Society on Ubiquitous Networks, 353-362 (2008)

14. Nehmer, J., Becker, M., Karshmer, A., Lamm, R.: Living assistance systems: an ambient intelligence approach. In: Proceedings of the 28th international conference on Software engineering, pp. 43-50. ACM, Shanghai (2006)

15. Björklind, A., Holmlid, S.: Ambient Intelligence to Go. Santa Anna IT Research Institute $\mathrm{AB}(2003)$ 